\title{
TOP WEALTH SHARES IN AUSTRALIA 1915-2012
}

\author{
By Pamela Katic* \\ International Water Management Institute \\ AND \\ ANDREW LEIGH \\ Parliament of Australia
}

\begin{abstract}
Combining data from surveys, inheritance tax records, and rich lists, we estimate top wealth shares for Australia from World War I until the present day. We find that the top 1 percent share declined by two-thirds from 1915 until the late 1960s, and rose from the late 1970s to 2010. The recent increase is sharpest at the top of the distribution, with the top 0.001 percent wealth share tripling from 1984 to 2012. The trend in top wealth shares is similar to that in Australian top income shares (though the drop in the first half of the twentieth century is larger for wealth than income shares). Since the early twentieth century, top wealth shares in Australia have been lower than in the U.K. and U.S.
\end{abstract}

\section{INTRODUCTION}

The study of wealth inequality in Australia has a distinguished heritage. In a famous 1914 paper, Italian statistician Corrado Gini drew on inheritances and land values collected by the state of Victoria in the early 1910 s. $^{1}$ The high quality of Australian national statistics compiled and analyzed by statisticians such as Timothy Coghlan and G. H. Knibbs meant that in the decades after Federation, Australia not only enjoyed some of the highest living standards in the world, but had some of the best statistics in the world.

Unfortunately, the fragmentary nature of information on Australian wealth holdings has been reflected in the scholarship on the topic. Most studies have used a couple of wealth surveys, a few years of inheritance tax data, or a few years of rich lists. Because each data source has its limitations, there are advantages in drawing them together. In this sense, our project is a little like an impressionist painting: out of many different data points, we hope to produce a work that provides deeper insights into the subject.

*Correspondence to: Pamela Katic, IWMI-Ghana, CSIR Campus, PMB CT 112, Cantonments, Accra, Ghana (P.Katic@cgiar.org).

${ }^{1}$ Gini (1914), translated into English by Giovanni Maria Giorgi, and republished as Gini (2005). 
Our analysis of top wealth shares is grounded in three sources: wealth surveys, inheritance tax records, and rich lists. In each case, we have endeavored to draw upon all of the available data from the twentieth century onwards. ${ }^{2}$

To preview our results, we find a considerable reduction in top wealth shares across the period from World War I to the late 1970s, followed by a steady increase thereafter. Australian wealth inequality appears to track income inequality quite closely.

The remainder of the paper is structured as follows. Section 2 discusses the methodology for estimating wealth inequality, and the key literature. Section 3 presents estimates of top wealth shares, combining results from our three methods. Section 4 concludes.

\section{Methodology}

In their survey of wealth inequality, Davies and Shorrocks (2000) identify five possible data sources for estimating the distribution of wealth: wealth surveys, inheritance tax records, rich lists, wealth tax data, and investment income data. We cannot use wealth tax data (since Australia did not have a broad-based wealth tax), and we opt not to use the investment income approach due to its heavy reliance on assumed rates of return. This approach uses the amount of investment income stated on income surveys, and scales this up using assumed rates of return. It has been applied by a number of Australian studies (e.g., Dilnot, 1990; Bækgaard and King, 1996; Kelly, 2001). However, it depends on the assumption that all assets are income-earning (which misses wealth held in primary residences, motor vehicles, boats, artworks, etc.), and ignores heterogeneity in rates of return. Top 1 percent simulated estimates by Kelly (2001) using this approach range between 11 and 13 percent for the period 1986-98, which are close to our estimates using the HILDA database (11 to 16 percent for the years 2002, 2006, and 2010).

Below, we discuss in turn the three data sources that we use to create our estimates of top wealth shares in Australia. We then present the results in graphical form, combining estimates using different methodologies. Appendix Tables A1, A2, and A3 separately set out the results from each methodology.

\subsection{Wealth Surveys}

Of the three sources, wealth surveys are the most reliable for judging wealth inequality, since they have good coverage across the population (except perhaps at the very top of the distribution: see Moore et al., 2000), and aim to cover multiple sources of wealth and debt. The main challenge that arises is one of comparability. This may arise in how wealth is surveyed. For example, a survey that asks about 20 sources of wealth is likely to come up with a different estimate than one which only asks about two sources of wealth. Another issue is the unit of analysis. While wealth surveys almost always ask about total household wealth, some then report a single

\footnotetext{
${ }^{2}$ For the 18 th and 19 th centuries, there is relatively little material available on wealth inequality. Exceptions include Thomas (1991), who estimates the share of land grants in 1788-1821 that went to the top groups; and Rubinstein (2004), who estimates the "all time" richest 200 Australians over the period 1788-2004. For a more extensive discussion, see Leigh (2013).
} 
observation per household, while others report one observation per person. The effect of the former approach is to underweight large households in any analysis.

Our analysis draws upon five Australian wealth surveys: one for which we have only tabulations, and four for which we have microdata. We begin with the war survey of 1915, conducted by the Commonwealth Bureau of Census and Statistics (the precursor to the Australian Bureau of Statistics). This survey arrived at a final wealth figure by asking 21 questions about assets and three questions about debts. The results were meticulously tabulated and analyzed at the time by Knibbs (1918), and we use these tabulations in our analysis. Although Knibbs suggested at the time that Australia should conduct a decennial census of wealth, wealth has never been included in the Australian census.

The next survey we use is the 1987 Australian Standard of Living Study, which asked about six categories of wealth, as well as whether respondents had a home mortgage. ${ }^{3}$ We use the microdata from this survey to carry out our analysis. After this, we use the Household, Income and Labour Dynamics in Australia (HILDA) Survey. HILDA included questions about wealth in its 2002, 2006, and 2010 surveys, and we use microdata from each of these waves. Our analysis was kindly carried out for us by the Melbourne Institute's Roger Wilkins. We drop all respondents aged under 18, and divide household wealth by the number of responding adults in the household. ${ }^{4}$

There are other Australian wealth surveys that we opt not to use. The 1966-67 Australian Survey of Consumer Finances and Expenditures (see Podder and Kakwani, 1976; Schneider, 2004) appears to underweight large households, and we opt not to use it on the basis that our inheritance tax records cover this period. The 1994 National Social Science Survey lists all items in categories (rather than dollar amounts), and does not allow us to subtract mortgage debt. And the ABS Household Wealth and Wealth Distribution Surveys (conducted in 2003-04, 2005-06, 2009-10) are harder to analyze than the HILDA survey due to the well-known difficulties in analyzing ABS microdata.

The precise wording of the wealth questions in the surveys that we use are set out in Appendix I.

The final methodological point worth making on the use of surveys to estimate top shares is that they will be sensitive to sampling error. For expositional simplicity, we do not report standard errors in the tables and graphs that follow. But bootstrap estimations suggest that the standard errors are between 0.2 and 1 percentage points for the 10 percent, 1 percent, and 0.1 percent shares. Expressed in terms of percentage points, standard errors tend to be smaller for the higher percentiles. Comparing the standard errors with the point estimates, this equates

${ }^{3}$ The 1987 survey is the data source that we are least confident about (indeed, the second author opted not to use it in another study; see Leigh, 2007). We incorporate it here because it is the only available data point between $1978-79$ and 2002.

${ }^{4}$ To test the impact of ignoring wealth inequality within households, for each household, we summed personal wealth and assigned total household wealth (being the sum of personal wealth and shared household wealth) to individuals in proportion to their share of personal wealth. The impact of this approach was to introduce some degree of wealth inequality within households. Using this approach increased both the top 1 percent share and the top 0.1 percent share by about one-fifth. This suggests that our results may slightly underestimate the increase in inequality from the 1970 s to the 2000 s. 
to relative standard errors in the range of 5 to 15 percent. Expressed in relative terms, standard errors tend to be larger for the higher percentiles.

\subsection{Inheritance Tax Records}

The use of inheritance tax records to estimate inequality dates back to the work of Coghlan (1906) and Mallet (1908). Underlying this approach is that the dead are representative of the living. In effect, this approach "blows up" the inheritance tax distribution by multiplying it by the inverse of the mortality rate. Put another way, if death is a random sampling technique, then the inheritance tax returns can give us an unbiased estimate of wealth inequality among the living.

As Atkinson (2008) points out, researchers such as Coghlan (1906) and Young (1917) were quick to note that tabulations that did not separate deceased estates by age and gender were not particularly informative. Because the distribution of wealth tends to fan out over the life course, it is necessary to take account of the age at death if one is to properly convert inheritance tax data to wealth inequality. In addition, it is necessary to account for the fact that the rich tend to outlive the poor, by making some form of social mortality adjustment.

These issues make much of the available inheritance tax data unusable, since it does not contain tabulations of estate size by age and gender. In benchmarking the results of the war census against the inheritance tax returns, Knibbs (1918) uses data from the Victorian and New South Wales probate tax returns. However, these appear to be custom tabulations, as the tables published in the state yearbooks of the era do not provide such a level of disaggregation. After extensive contact with the Australian Taxation Office, we have only been successful in obtaining inheritance tax tabulations at the national level for the period 1953-54 to 1978-79. These tabulations present the number of people in each taxable estate bracket, disaggregated by gender and age group. Prior to 1953, it appears that the Australian Taxation Office did not tabulate inheritance tax returns by age and gender. The Australian inheritance tax was abolished on July 1, 1979. For more detail on the operation and abolition of Australian inheritance taxes, see Pedrick (1981), Saunders (1983), Duff (2005), and Gilding (2010).

For each date and gender cell, we compute the estate multiplier as the product of the average mortality from the cell (sourcing historical Australian mortality rates from the Mortality Database by Wilmoth and Shkolnikov, 2012) and the social differential mortality factor from Clarke and Leigh (2011). We multiply the number of decedents by the estate multiplier and obtain a distribution of gross estate brackets for the living population. We then estimate the amounts corresponding to each fractile $(0.05$ percent, 0.1 percent, 0.25 percent, 0.5 percent, 1 percent, and 2 percent) using a Pareto approximation (Kopczuk and Saez, 2004) and net worth estimates from Gunton (1975) and the Australian Treasury (2007) that serve as total wealth denominators (see Table A4 in the Appendix). For some years, the estate tax data does not cover the top 0.05 percent of the population (i.e., they are in an open upper interval). Here we assume that the Pareto coefficient is the same as the one for the top 0.1 percent. Since the parameters vary considerably over two or more groups, if the data also did not cover the 0.1 percent and/or 0.25 percent, we applied the parameters obtained in the closest year with full data. 
To date, other researchers have made only partial use of Australian inheritance tax data. Gunton (1975) presents estimates for 1953 to 1969 (but without adjusting for social mortality differences), while Ablett (1983) reports wealth inequality estimates for 1976-77. Other estimates include Harrison (1979), who re-analyzes the estimates for 1967-68 that were presented in Gunton (1971), and Raskall $(1977,1978)$, who averages inheritance tax data for 1966-67 to 1972-73. Other noteworthy research includes an extensive literature review by Piggott (1984), and an analysis of inequality of Victorian estates by Rubinstein (1979), which covers a long time span (1860-1974), but does not account for the age of the deceased. Similarly, Shanahan (2001) analyzes estate records from South Australia in 1905-15 (without accounting for socioeconomic differences in mortality). His study estimates that the top 1 percent then held around 30 percent of wealth.

Our results are adjusted using the social mortality multiplier of Clarke and Leigh (2011), who analyze survey respondents who participated in the HILDA survey during 2001-07, and then subsequently died. The authors find that the relative risk of mortality between the poorest and richest income quintile was 1.9 times higher, and this translated into a life expectancy gap (at age 20) of six years. They also note that area-level incomes have no significant impact on mortality risk (after controlling for individual characteristics), which suggests that an individuallevel mortality analysis is likely to be more precise than a regional-level mortality analysis. In our analysis of inheritance tax data, we assume a mortality-wealth gradient that matches Clarke and Leigh's mortality-income gradient.

There are limitations to the precision of these estimates. Estimates based on inheritance tax returns could be biased by tax underreporting, which could potentially have grown over time. Although the Australian inheritance tax in theory covered all real and personal property, it is possible that individuals managed to find innovative ways of avoiding the tax at a more rapid rate than the tax authorities and legislators were able to prevent such avoidance. ${ }^{5}$ Our estimates also suffer from measurement error within age-gender cells (we use tables that present figures in ten-year age bands) and within wealth cells. ${ }^{6}$ It is also possible that the mortality-wealth gradient has changed over time.

Unlike the other two data sources, our inheritance tax estimates cover tax years, which in Australia run from July 1 to June 30. For expositional simplicity, we refer to tax years by the starting year (for example, we refer to the tax year $1978-79$ as "1978").

\subsection{Rich Lists}

In 1983, Business Review Weekly (now known as BRW Magazine) began publishing an annual list of the richest Australians. While ad hoc rich lists have a

${ }^{5}$ Details of the coverage of the Australian inheritance tax may be found in the Estate Duty Act 1914 (Cth) and the Estate Duty Assessment Act 1914 (Cth). The legislation contained extensive provisions about the treatment of gifts prior to death. Assets were to be valued at market value, and could be challenged via the Valuation Board.

${ }^{6}$ Since deaths are a sample of the population, estimates of wealth inequality derived from inheritance tax returns are in principle also subject to sampling error. Following Kopczuk and Saez (2004), we do not attempt to estimate standard errors for our estimates, but refer the interested reader to Atkinson and Harrison (1978) for a more extensive treatment of the issue. 
long lineage, annual rich lists are a more recent phenomenon, with Forbes Magazine commencing its U.S. rich list in 1982, and the Sunday Times commencing its U.K. rich list in 1989.

Surprisingly little use has been made of these lists by Australian economists. Exceptions include Siegfried and Round (1994), who analyze the competitiveness of industries in which rich-listers made their fortunes, and careful descriptive work by sociologists and heterodox economists (Gilding, 1999; Stilwell and Ansari, 2003; Stilwell and Jordan, 2007; Chesters, 2011; Murray and Chesters, 2012).

Atkinson (2008) lists a number of limitations of rich lists. First, wealth information may not be public, and subsequent inquiries can throw up additional information. For example, in 2005, journalist Stephen Mayne published the "Crikey Revised Wealth" rich list: pointing to what he regarded as errors or omissions in the BRW 200 rich list. Second, even when assets are known, it may be difficult to value them accurately. Third, the choice to list families or individuals can significantly affect the rich list ranking. Fourth, assets can be more visible than debts (Atkinson gives the example of Robert Maxwell, who was listed on the U.K. rich list before his death revealed massive debts). And fifth, geographic criteria can be somewhat arbitrary. For example, the BRW rich list continued to include Rupert Murdoch until 1995, despite the fact that Murdoch renounced his Australian citizenship in 1985.

We focus on the 1984-2012 rich lists, which cover around 200 people or families (we drop the 1983 rich list, which included only about 100 people). With Australia's adult population rising from 11 million to 18 million during this period, the BRW 200 rich list therefore comprises between 0.0018 and 0.0011 percent of the adult population. For consistency, we estimate the share of wealth held by the richest 0.001 percent of adults, which equates to approximately the 110 richest people in earlier years, and 180 in later years. We also estimate the wealth share of the top 0.0001 percent (which is based on the wealth of the richest 11 to 18 people). In both cases, we use an external wealth denominator, being household private wealth estimates from the Australian Treasury and the Australian Bureau of Statistics, appropriately spliced. ${ }^{7}$ [Correction added on 06 March 2015, after first online publication: In the above statement, the rise in Australia's adult population, BRW 200 rich list percentages, share of wealth held by the richest 0.001 percent of adults and share of the top 0.0001 percent were previously incorrect. These have now been amended in this version.]

Following Atkinson (2008), we also look at inequality within the rich list, by estimating the Gini coefficient within the rich list and the share of wealth held by the top one-quarter. Exploiting an additional feature of these data, we also estimate the share of rich list wealth held by women (excluding family holdings for the

\footnotetext{
${ }^{7}$ The two wealth series are a Treasury wealth series, most recently published as Goldbloom and Craston (2008) (covering 1960-2007), and ABS 2012 (Australian Bureau of Statistics, 2012) (covering 1991 onwards). Over the overlap period (1991-2007), the Treasury wealth series is 93 percent of the ABS wealth series. Conceptually, the Treasury series is slightly closer to the BRW wealth concept, since it consolidates the household and business sectors, and values assets of unincorporated entities at market value (rather than replacement cost). We therefore use the Treasury series as the household wealth denominator for 1984-2007, and then use the ABS household wealth estimate for 2008-12, scaled down by a factor of 0.93 .
} 
purposes of this analysis). For these three purposes, we use everyone that appears on the rich lists.

\section{Estimating Top Wealth Shares}

In Figure 1a, we present our estimates of top 1 percent wealth share. In 2010, this group is those households with a per-adult wealth of \$2.4 million or more. Our estimates combine survey data and inheritance tax data for the period 1915-2010. The series starts with 1915, when we estimate that the top 1 percent held 34 percent of all household wealth; a similar figure to that estimated by Shanahan (2001) for South Australia in the early-twentieth century. By 1953 when our inheritance tax series starts, the top 1 percent share was down to 15 percent. The next year, this was down to 11 percent, and fluctuated around 10 percent through the rest of the 1950s.

(a) Top 1 percent wealth share

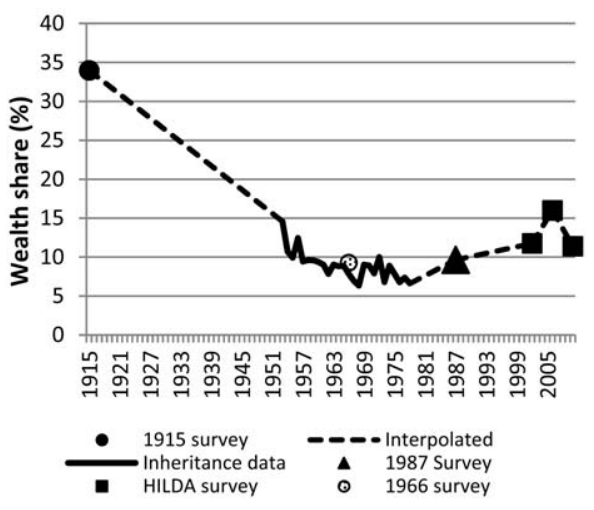

(b) Top 0.1 percent and 0.5 percent wealth shares

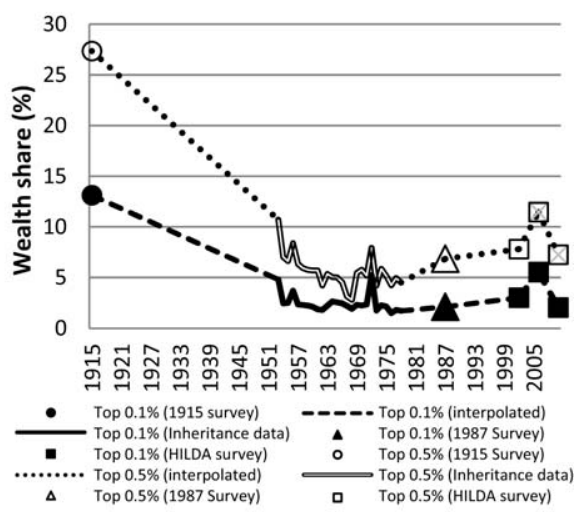

(c) Share of top 1 percent wealth held by women

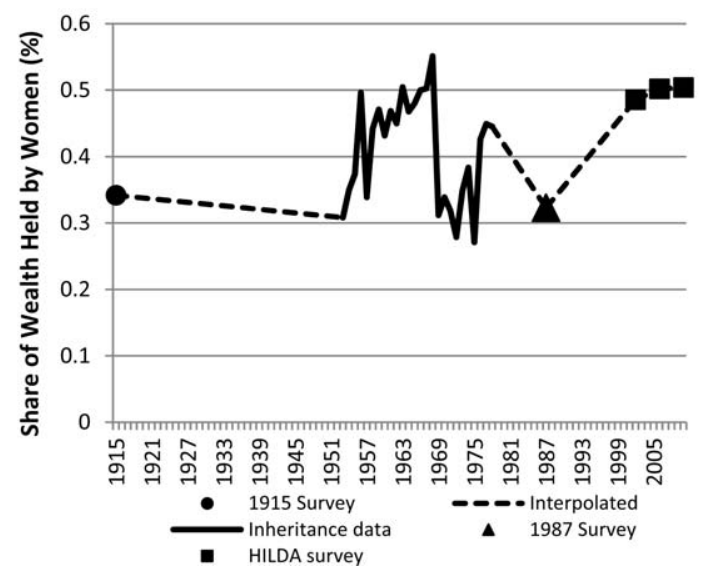

Figure 1. Top Wealth Shares 
In the 1960 s wealth concentration declined further still, with the top 1 percent share reaching its lowest point in 1968 at 6 percent. Wealth inequality then rose slightly during the 1970s, with our last inheritance tax estimate being 7 percent in 1978 (the tax was then abolished). ${ }^{8}$ Our next estimate is a survey-based estimate of 10 percent in 1987, suggesting a modest rise in wealth inequality during the $1980 \mathrm{~s}$. We then have another break until 2002, when we estimate that the top 1 percent held 12 percent of household wealth. This estimate rises to 16 percent in 2006, before falling back to 11 percent in 2010 .

This estimate seems to suggest a rise in top wealth inequality in 2006, but we are cautious about reading too much into the estimate, since it seems to be driven by a small number of respondents in the survey. For example, if we exclude the top 0.1 percent (between 13 and 20 respondents in the HILDA dataset), and estimate the income share of those between the 99th and 99.9th percentiles, the estimates are 8.7 percent (2002), 10.5 percent (2006), and 9.4 percent (2010).

More generally, since it is recognized that survey estimates tend to produce lower estimates of top wealth shares than inheritance tax estimates (Piketty, 2014), it is likely that our approach understates both the modern-day level of wealth inequality in Australia, and the upward trend since the late 1970s. Similarly, because the 1915 estimate is survey-based, it is possible that the fall in Australian wealth inequality between the 1910s and the 1950s was even more dramatic than our numbers suggest.

Examination of the very top groups in Figure $1 \mathrm{~b}$ (top 0.1 percent and 0.5 percent) helps to explain the overall pattern in Figure 1a. To put these figures into perspective, in the 2010 survey, the top 0.5 percent are households with a perperson wealth exceeding $\$ 3.4$ million, while the top 0.1 percent are households with a per-person wealth exceeding $\$ 6.1$ million.

The top 0.1 percent held 13 percent of total wealth in 1915. This share dropped to 5 percent in 1953 and was down to 2 percent by 1957 . The top 0.1 percent share remained at around 2 percent of total wealth for much of the next half-century, with the exception of one-off spikes in 1972 and 2006. As Figure 1b illustrates, the top 0.5 percent share explains most of the top 1 percent and 2 percent movements: a fall in the initial 50 years and an increase from the early 1970s. Thus, the movements of the top 1 percent and 2 percent shares are primarily due to changes taking place within the very top of the top 1 percent. $^{9}$

Figure 1c displays the percentage of women within the top 1 percent group. The fraction of women among top wealth holders almost doubled from 30 percent in 1915 to 55 percent in 1968. After a sudden decline in the early 1970s, the fraction of top 1 percent wealth held by women continued to fluctuate until the late 1970s. In 2010, women held 50 percent of the top 1 percent wealth in Australia. These levels and trends are similar to the U.S. (Kopczuk and Saez, 2004). Overall, there

\footnotetext{
${ }^{8}$ The top shares are not significantly sensitive to the social differential mortality factor. For example, placing the assumptions at the extremes of their confidence intervals affects the top 1 percent shares by less than 1 percentage point and does not alter their historical pattern.

${ }^{9}$ Estimates of shares-within-shares follow a similar pattern as the top 0.1 percent shares. For example, the share of top 1 percent wealth held by the top 0.1 percent is 0.39 in $1915,0.23$ in $1960-61$, 0.25 in $1970-71,0.26$ in $2002,0.35$ in 2006 , and 0.18 in 2010 . We believe the volatility in the final three years reflects the small sample used to estimate the top 0.1 percent share in survey data.
} 
(a) Comparing Top $1 \%$ Wealth and Income Shares

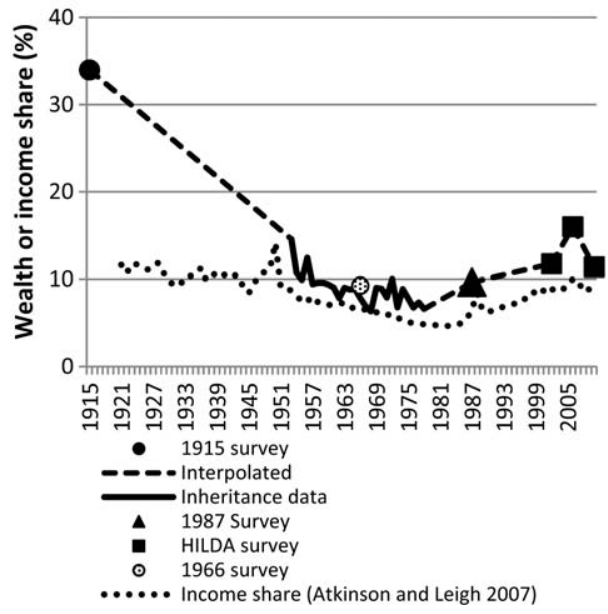

(b) Wealth to Income Ratio

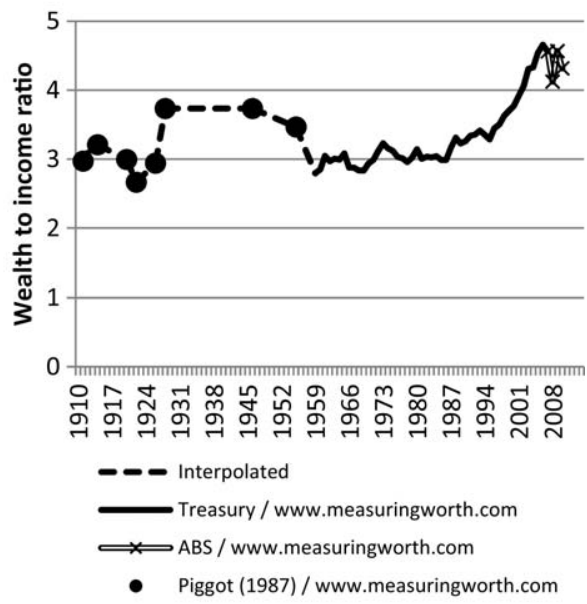

Figure 2. Income and Wealth

has been considerable (but variable) gender equalization in the holding of wealth over this period.

Comparing top wealth shares to top income shares, Figure 2a indicates that the drop in inequality during the first half of the twentieth century is more dramatic for wealth than for income. ${ }^{10}$ While we estimate that the top 1 percent wealth share fell by two-thirds from 1915 to 1953, Atkinson and Leigh (2007) estimate that the top 1 percent income share fell from 12 percent in 1921 to 9 percent in 1953. Over the post-war decades, top income shares fell more sharply than top wealth shares, with the top 1 percent income share nearly halving (to 5 percent) from the early 1950 s to the late 1970 s. And from 1978 to $2009-10$, the increase in top 1 percent wealth shares has been similar to the increase in top 1 percent income shares, with the top 1 percent wealth share rising from 6 to 11 percent, and the top 1 percent income share rising from 5 to 9 percent.

Recent work by Piketty and Zucman (2014) and Piketty (2014) has suggested that a key driver of inequality may be the wealth to income ratio. Accordingly, we drew on a variety of published sources on total wealth (Piggott, 1987; Australian Treasury, 2007; Australian Bureau of Statistics, 2012), and combined these with estimates of total GDP to estimate the wealth/income ratio in Australia. This approach follows the way in which Piketty (2014) calculates some of his measures of wealth to income ratios. Figure $2 b$ shows the result of this exercise.

Over the first part of the century, we do not see strong evidence that the wealth/income ratio tracks top wealth shares, with the ratio rising from around 3 in

${ }^{10}$ For the top 0.1 percent share, the pattern is broadly similar, though there are some years in which the top 0.1 percent income share exceeds the top 0.1 percent wealth share. Inspired by Piketty and Zucman (2014), we also estimated the wealth/income ratio in Australia. This was 6 in 1960, 6.14 in 1970, 4.35 in 1980, 5.99 in 1990, 7.49 in 2000, and 9.1 in 2010. We thank one of our reviewers for suggesting this exercise. 


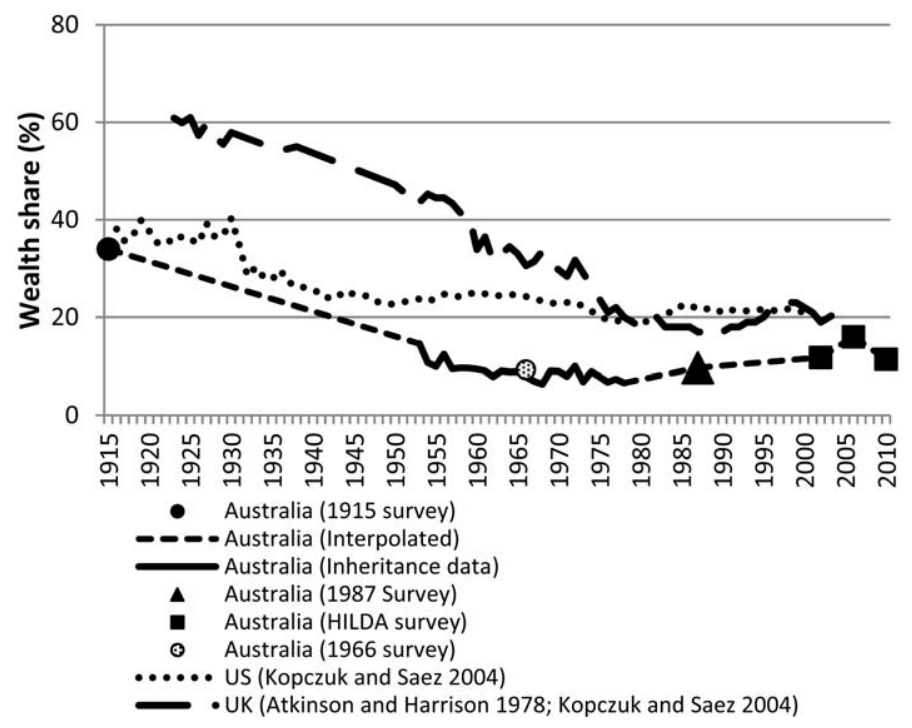

Figure 3. The Top 1 Percent Wealth Share in Australia, U.S., and U.K.

the period 1910-30 to around 3.7 in 1930-50, before falling back to around 3 in the era 1950-85. However, in the period from 1985 onwards, the wealth/income ratio rose steadily, to be around 4.5 in 2010 . This was its highest level over the century 1910-2010.We now compare the Australian top wealth series with comparable series constructed using the estate multiplier technique for the U.S. (Kopczuk and Saez, 2004) and the U.K. (Atkinson and Harrison, 1978, p. 159, for years up to 1972; U.K. Inland Revenue statistics cited in Kopczuk and Saez, 2004, for 1976 onwards.). In all three countries, top wealth shares fell throughout the 1915-2010 period (Figure 3). The U.S. displays the smallest drop in this period, with wealth declining from 38 to 19 percent. In contrast, the U.K. decline is the most dramatic: the top 1 percent held around 61 percent of national wealth in 1923, but this share declined steeply to 20 percent by the end of the 1970s, converging with the U.S. series. Finally, Australian top wealth holders held a significantly lower share of national wealth in this period than in the U.S. or the U.K.

Moving further up the distribution, Figure $4 \mathrm{a}$ shows estimates of the top 0.001 percent and the top 0.0001 percent, drawn from the annual rich lists compiled by $B R W$ Magazine. We find that both shares have risen over this period. From 1984 to 2012, the top 0.001 percent (the richest $1 / 100,000$ th of the adult population) tripled its share of household wealth from 0.9 percent to 2.9 percent. It is worth mentioning that in 2010 , the 0.001 percent share is greater than the 0.1 percent share reported in Figure 1b. This is likely evidence that the HILDAderived series are underestimates, as previously mentioned. Over the same period, the top 0.0001 percent (the richest one-millionth of the adult population) quintupled its share of household wealth from 0.3 percent to 1.5 percent. This rapid rise is consistent with what has been observed by Kopczuk and Saez (2004) for the top 0.0002 percent wealth share in the U.S. [Correction added on 06 March 2015, after 
(a) Top 0.001 percent and 0.0001 percent wealth shares

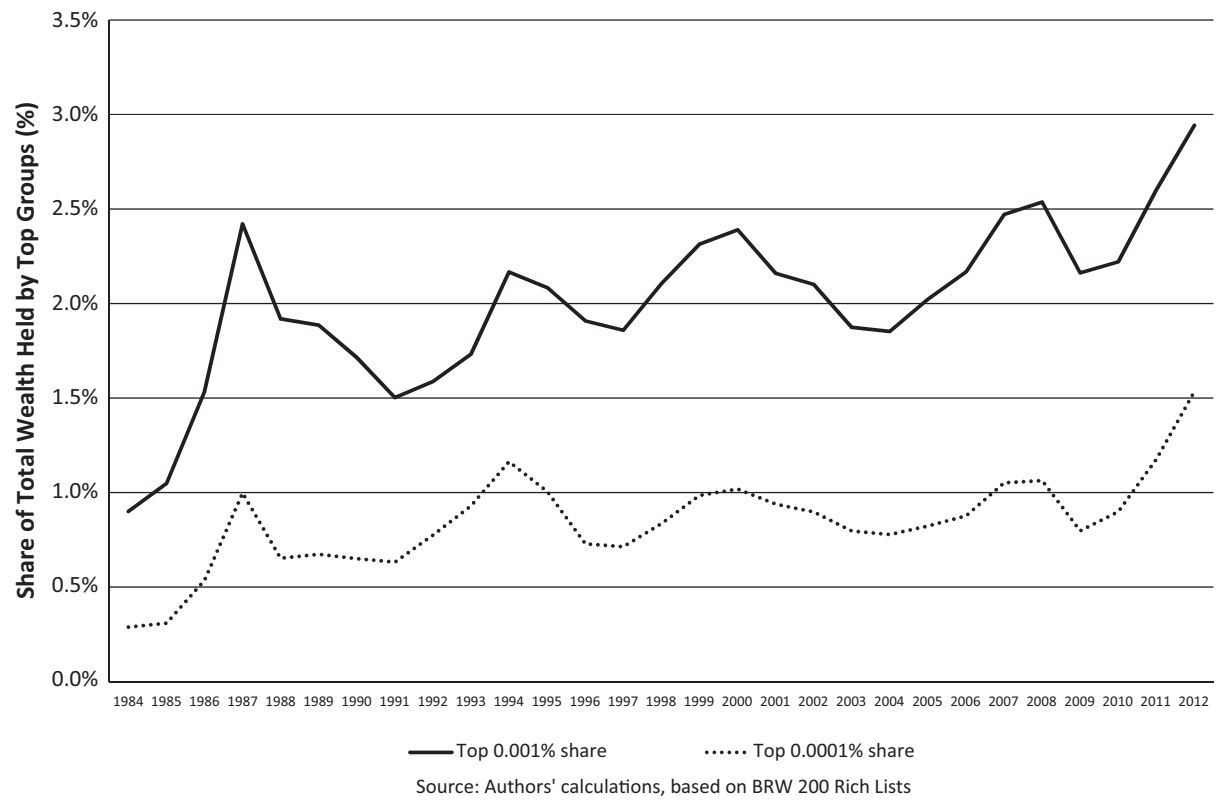

(b) Gini coefficient and top quartile share

(c) Share of rich 200 wealth held by women
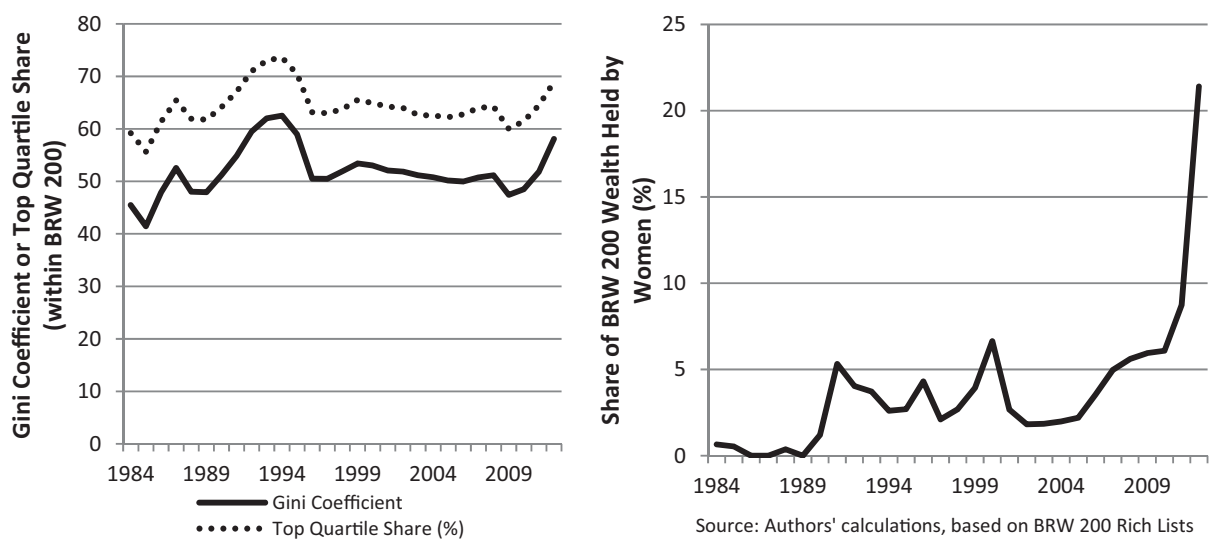

Source: Authors' calculations, based on BRW 200 Rich

Figure 4. Wealth Inequality among the Richest 200 Australians [Correction added on 06 March 2015, after first online publication: Figure 4a has been amended in this version.]

first online publication: In the above statement, the percentage for the tripling and quintupling of the share of household wealth have been amended in this version.]

Figure $4 \mathrm{~b}$ uses all members of the rich list, and estimates inequality among the super-rich. This shows a less marked upwards trend than Figure 4a, with the Gini coefficient among rich listers rising from 0.45 in 1984 to above 0.6 in 1992-94, before falling to around 0.5 for the following decade. In 2012, the rich list Gini rose 
to 0.6. Interestingly, the Gini for household net wealth across the population is around 0.6 in the HILDA surveys (2002, 2006, and 2010). This suggests that wealth inequality within the super-rich is similar to the level of wealth inequality across the entire population.

The share of rich list wealth held by the top quartile followed a very similar pattern, starting at around 60 percent in the mid-1980s, rising to 75 percent in 1994, dropping back to 60 percent, and rising to 71 percent in 2012. This figure is similar to that which was estimated by Atkinson (2008) for the super-rich in Germany and the United States.

In Figure 4c, we also estimate the share of super-rich wealth that is held by women, and observe a significant increase over the three decades for which we have data, with the share rising from 0.6 percent in 1984 to at least 2 percent since 1991. In 2012, the share of rich list wealth held by women leaped to 21 percent, a rise that was largely due to the surging mining wealth of Australia's richest woman, Gina Rinehart. Excluding Rinehart, the share of rich list wealth held by women in 2012 would have been 3 percent - an order of magnitude below the share of top 1 percent wealth held by women (Figure 1c).

\section{Conclusion}

Using data from surveys, inheritance tax records, and rich lists, we estimate wealth inequality over the period 1915-2010. We observe a dramatic drop from World War I to the 1950s, followed by a steady decline during the 1950s and 1960s. Since the late 1970s, top wealth shares in Australia have risen substantially, with the top 1 percent share rising from 7 percent in 1978 to 11 percent in 2010. Even allowing for some sampling error in the recent surveys, we can say with a high degree of confidence that wealth inequality has risen. As with top income shares, the increase in inequality has been even more pronounced at the top of the distribution, with the top 0.001 percent wealth share tripling from 1984 to 2012. Wealth inequality has risen not only across the population, but even within the BRW rich list. Australia's level of top wealth inequality may be lower than the U.K. and U.S., but the rise over recent decades has been significant nonetheless.

What factors drove the fall and rise of wealth inequality in Australia? Leigh (2013) argues that three predominant factors explain the U-shape pattern of income and wealth inequality in Australia: taxation; globalization and technology; and unionization (with some offsetting contribution from education). In understanding trends at the very top of the distribution, the first two explanations are likely to be the most important. In the case of taxation, income tax rates increased from the 1910s to the 1950s, and fell during the 1980s and 1990s. Similarly, the abolition of federal inheritance taxes in 1979 is likely to have increased wealth inequality over subsequent decades (although the introduction of broad-based capital gains taxation in 1985 is likely to have had a countervailing impact).

In terms of globalization and technology, restrictive trade policies in the interwar and post-war decades may have limited the market reach of Australia's largest firms. Since the early 1980s, the globalization of "superstar" labor markets (such as for CEOs) probably contributed to more inequality in English-speaking countries. Skill-biased technological change likely contributed to some portion of 
the rise in top income inequality (and therefore in top wealth inequality) during the past three decades. However, to explain concentration at the very top tail, a further mechanism needs to be introduced, generating greater dispersion within the skilled group. The global financial crisis has been a wealth leveler, bringing a reduction in inequality because high-income households have a larger share of their wealth in high-risk asset classes, which fell in value between 2006 and 2010.

\section{REFERENCES}

Ablett, J. R., "The Distribution of Wealth and the Case for Annual Net Worth Taxation," C.E.D.A. Monograph No. 1472, 1983.

Atkinson, A. B., "Concentration among the Rich" in J. B. Davies (ed.), Personal Wealth from a Global Perspective, Oxford University Press, Oxford, 64-89, 2008.

Atkinson, A. B. and A. J. Harrison, Distribution of Personal Wealth in Britain, Cambridge University Press, Cambridge, 1978.

Atkinson, A. B. and A. Leigh, "The Distribution of Top Incomes in Australia," Economic Record, 83, 247-61, 2007.

Australian Bureau of Statistics, Australian System of National Accounts, Cat. No. 5204.0, ABS, Table 38, Canberra, 2012.

Australian Treasury, Australian Net Private Wealth, Australian Government Treasury, Canberra, 2007.

Bækgaard, H. and A. King, "Modelling the Accumulation and Distribution of Australian Household Assets," Paper presented to the 24th General Conference of the International Association for Research in Income and Wealth, Lillehammer, 1996.

Chesters, J., "Wealth Inequality in Australia 1989-2010," Paper presented at the Australian Sociological Association "Local Lives/Global Networks Conference" November 28-December 1, 2011, University of Newcastle, Newcastle, 2011.

Clarke, P. and A. Leigh, "Death, Dollars and Degrees: Socio-Economic Status and Longevity in Australia," Economic Papers, 30, 348-55, 2011.

Coghlan, T., "Discussion," Journal of the Royal Statistical Society, 69, 735-36, 1906.

Davies, J. B. and A. F. Shorrocks, "The Distribution of Wealth," in A. B. Atkinson and F. Bourguignon (eds), Handbook of Income Distribution, North-Holland, Amsterdam, 605-75, 2000.

Dilnot, A. W., "The Distribution and Composition of Personal Sector Wealth in Australia," Australian Economic Review, 1, 33-40, 1990.

Duff, D., "The Abolition of Wealth Transfer Taxes: Lessons from Canada, Australia and New Zealand," Pittsburgh Tax Review, 3, 71-120, 2005.

Gilding, M., "Superwealth in Australia: Entrepreneurs, Accumulation and the Capitalist Class," Journal of Sociology, 35, 169-82, 1999.

, "The Abolition of Death Duties in Australia: A Comparative Perspective," Paper presented at "Social Causes, Private Lives," the Annual Conference of the Australian Sociological Association (TASA 2010), Sydney, 2010.

Gini, C., "Sulla misura della concentrazione e della variabilità dei caratteri," Atti del Reale Istituto Veneto di Scienze, Lettere ed Arti, 73, 1203-48, 1914.

- "On the Measurement of Concentration and Variability of Characters," METRONInternational Journal of Statistics, 63, 3-38, 2005.

Goldbloom, A. and A. Craston, "Australian Household Net Worth," Economic Roundup, Summer 2008, Australian Treasury, Canberra, 2008.

Gunton, R., "A Distribution of Personal Wealth in Australia: 1967-68," Paper delivered at 43rd ANZAAS Congress, Brisbane, 1971.

—. Personal Wealth in Australia, Unpublished PhD Thesis, University of Queensland, Brisbane, 1975.

Harrison. A., "The Distribution of Wealth in Ten Countries," Royal Commission on the Distribution of Income and Wealth, Background Paper to Report No. 7, HMSO, London, 1979.

Kelly, S., "Trends in Australian Wealth: New Estimates for the 1990s," Paper presented to the 30th Annual Conference of Economists, September 23-26, University of Western Australia, Crawley, 2001.

Knibbs, G. H., The Private Wealth of Australia and its Growth, Commonwealth Bureau of Census and Statistics, Melbourne, 1918. 
Kopczuk, W. and E. Saez, "Top Wealth Shares in the United States, 1916-2000: Evidence from Estate Tax Returns," National Tax Journal, 57, 445-87, 2004.

Leigh, A., "Intergenerational Mobility in Australia," BE Journal of Economic Analysis \& Policy, 7, $1-28,2007$.

- Battlers and Billionaires: The Story of Inequality in Australia, Black, Melbourne, 2013.

Mallet, B., "A Method of Estimating Capital Wealth from the Estate Duty Statistics," Journal of the Royal Statistical Society, 71, 65-84, 1908.

Moore, J. C., L. L. Stinson, and E. J. Welniak, "Income Measurement Error in Surveys: A Review," Journal of Official Statistics, 16, 331-62, 2000.

Murray, G. and J. Chesters, "Economic Wealth and Political Power in Australia, 1788-2010," Labour History, 103, 1-15, 2012.

Pedrick, W., "Oh, to Die Down Under! Abolition of Death and Gift Duties in Australia," Tax Law, 35, $113-41,1981$.

Piggott, J., "The Distribution of Wealth in Australia-A Survey," Economic Record, 60, 252-65, 1984. , "The Nation's Private Wealth-Some New Calculations for Australia," Economic Record, 63, 61-79, 1987.

Piketty, T., Capital in the Twenty-First Century, Harvard University Press, Boston, MA, 2014.

Piketty, T. and G. Zucman, "Capital is Back: Wealth-Income Ratios in Rich Countries, 1700-2010," Quarterly Journal of Economics, 129, 1255-310, 2014.

Podder, N. and N. C. Kakwani, "Distribution of Wealth in Australia," Review of Income and Wealth, 22, 75-92, 1976.

Raskall, P., The Distribution of Wealth in Australia, 1967-72, Planning Research Centre, University of Sydney, Sydney, 1977.

, "Who Got What in Australia: the Distribution of Wealth," Journal of Australian Political Economy, 2, 3-16, 1978.

Rubinstein, W. D., "The Distribution of Personal Wealth in Victoria 1860-1974," Australian Economic History Review, 19, 26-41, 1979.

, The All Time Australian 200 Rich List, Allen \& Unwin, Sydney, 2004.

Saunders, P., "An Australian Perspective on Wealth Taxation," in J. G. Head (ed.), Taxation Issues of the 1980s, Australian Tax Research Foundation, Sydney, 413-32, 1983.

Schneider, M., The Distribution of Wealth, Edward Elgar, Cheltenham, 2004.

Shanahan, M. P., "Personal Wealth in South Australia," Journal of Interdisciplinary History, 32, 55-80, 2001.

Siegfried, J. J. and D. K. Round, "How Did the Wealthiest Australians Get so Rich?" Review of Income and Wealth, 40, 191-204, 1994.

Stilwell, F. and M. Ansari, "Wealthy Australians," Journal of Australian Political Economy, 52, 143-57, 2003.

Stilwell, F. and K. Jordan, Who Gets What? Analysing Economic Inequality in Australia, Cambridge University Press, Melbourne, 2007.

Thomas, M., "The Evolution of Inequality in Australia in the Nineteenth Century," in Y. S. Brenner, H. Kaelble, and M. Thomas (eds), Income Distribution in Historical Perspective, Cambridge University Press, Cambridge, 149-73, 1991.

Wilmoth, J. R. and V. Shkolnikov, "The Human Mortality Database" (www.mortality.org; accessed October 20, 2012).

Young, A. A., "Do the Statistics of the Concentration of Wealth in the United States Mean What They Are Commonly Assumed to Mean?" Publications of the American Statistical Association, 15, 471-84, 1917.

\section{SUPPORTING INFORMATION}

Additional Supporting Information may be found in the online version of this article at the publisher's web-site:

Table A.1: Estimates from inheritance tax records

Table A.2: Estimates from survey records

Table A.3: Estimates from the BRW200 Rich Lists

Table A.4: Total wealth and average wealth (used in Pareto interpolation)

Appendix I: Wealth Survey Questions

Appendix II: Acknowledgements. 